\title{
Lessons Learned in the Use of WIRIS Quizzes to Upgrade Moodle to Solve Electrical Circuits
}

Santiago Bogarra, Montserrat Corbalán, Member, IEEE, Antoni Font, Inmaculada Plaza, Senior Member, IEEE, and Francisco Arcega, Senior Member, IEEE

Abstract-WIRIS quizzes is an online mathematics tool for educational purposes that upgrades Moodle quizzes, and allows the development of personalized quizzes using random data and conditional instructions. WIRIS quizzes can be used in any mathematics or science degree; its complex operators allow it to be used to solve electrical circuits. This tool promotes autonomous student learning and enables teachers to monitor that learning and make adjustments if necessary. Therefore, this tool improves teaching quality. It can also be used as an assessment tool by both the teacher and the student. This paper shows how WIRIS quizzes has been integrated into the virtual campus of the Polytechnic University of Catalonia (UPC), Spain to teach electrical circuits. Lessons learned in performing and using WIRIS quizzes with second year students at the UPC are shown.

Index Terms-Distance learning, e-learning, electrical engineering education, training, WIRIS quizzes Moodle

Manuscript received August 15, 2011. This work was supported in part by the "Institut de Ciències de l'Educació” of the Polytechnic University of Catalonia, the "Departamento de Ciencia, Tecnología y Universidad del Gobierno de Aragón" and the European Social Foundation.

S. Bogarra and A. Font are members of the Electrical Engineering Department, School of Industrial and Aeronautic Engineering in Terrassa (ETSEIAT)Polytechnic University of Catalonia (UPC), Terrassa 08222, Spain (e-mail: bogarra@ee.upc.es; fontp@ee.upc.es).

M. Corbalán is a member of the R\&D\&I EduQTech group - Electronics Engineering Department, School of Engineering of Terrassa (EET)- Polytechnic University of Catalonia (UPC), Terrassa 08222, Spain (e-mail: montserrat.corbalan@upc.edu).

I. Plaza Garcia is a member of the R\&D\&I EduQTech group - Electronics Engineering Department, Teruel Polytechnic, University of Zaragoza, Teruel (Spain) (e-mail: iplaza@unizar.es).

F. J. Arcega Solsona, is a member of the R\&D\&I EduQTech group - Electrical Engineering Department, Faculty of Engineering and Architecture, University of Zaragoza, Zaragoza (Spain) (e-mail: arcegafj@unizar.es). 


\section{INTRODUCTION}

ENGINEERING students traditionally request more problem solving to help them assess their learning. As mentioned by J.J. Rodríguez et al. [1], education is facing various challenges: the adequacy of the subject content to the emerging technologies of the 21st century; changes in the paradigm of education, and new and varied educational tools. The Polytechnic University of Catalonia (UPC), Spain, uses a Learning Management System (LMS), Moodle [2], which enables safe resource sharing because the student is authenticated on entry, and allows teachers to know what students are doing. The Moodle quiz module incorporates self-assessed quizzes that the student can do in or out of the classroom [3], which can be used both to assess the student and to teach the student to learn. R. Sharma [4] uses Moodle as a tool to enhance learning in both external and on-campus students. According to the IEEE Education Society Spanish Chapter, Moodle is the most-used LMS at all levels of study [5]. Aravinthan and Aravinthan [6] showed that there is a strong correlation between students who attempt the self-assessment training quizzes and those who perform well in terms of final marks. Peat et al. [7] also reach the same conclusions, but add that to really benefit from the resources students have to be sufficiently critical of their own performance. Woit and Manson [8] provide some evidence that online quizzes enhance learning in their target group. A student survey reflects an overall perception of improved grades and enhanced learning through online quizzes. WIRIS quizzes also help with autonomous learning, a skill that must be included in European Higher Education Area degree programs.

Various software packages are available for performing circuit analysis, among them PSpice, PSCAD or PSIM; these allow users to assemble component elements into a complete circuit and then to simulate the circuit's behavior [9], [10]. However, the steps involved in the mathematical solutions are not apparent to the user. Mallard, a software engine developed at the University of Illinois, was adapted by Bob Anderson at lowa State University to support the teaching of an introductory electrical circuits course [11]. The tool most similar to that presented in this paper is a 
Web-based system, CASTr, for training students in the framework of teaching electrical circuit theory [12], [13]. CASTr tracks students through all stages of their reasoning, rather than merely validating the final outcome. A new validation method of symbolic expressions was developed, based on node voltages and loop currents. In this paper, software was selected that allows not only the symbolic analysis of circuits, but also the solving of any electrical circuit or mathematics problems on engineering courses.

This paper shows that WIRIS quizzes [14]-[16], which upgrade Moodle, incorporate a powerful calculation tool. WIRIS tools were created by the Maths for More mathematical software company [14]. WIRIS quizzes offers new possibilities and fills the gap between the current Moodle question systems and the specific needs of the mathematics and science community. WIRIS is a computer algebra system with graphical and interactive capabilities, used to provide mathematical equivalence and to generate random questions via an algorithm. One of the most interesting functions of WIRIS quizzes is the possibility of adding random content. Moodle already does this to some extent, but is limited to choosing a random question from a group of preset questions, or mathematical expressions with only one random variable. WIRIS quizzes allows the integration of randomness at any level: in the question data, in a graph, or in the definition of a mathematical object. Moodle is far from being able to solve systems of equations, or operate with complex numbers, and offers only some functions (sine, exponential, etc). In addition, the syntax is less intuitive; for example, where Moodle uses pow $(x, 2)$ or pow(2, 1/2), WIRIS uses $x^{2}$ or $\sqrt{2}$.

WIRIS uses rational, irrational and complex numbers [17], [18], allows calculations with polynomials, vectors and matrices, and also includes a programming language that combines programming sentences with mathematical capabilities, for example the creation of a random matrix with rank three [19]. Specifically, in this study WIRIS quizzes is used to solve electrical circuits to encourage autonomous learning, because the quizzes or assignments are created to self-assess the key concepts. The quizzes were designed as quantitative questions, and 
recorded all the steps made by the student in order to achieve the final result. The experience consisted of weekly on-line quizzes. This would be an impossible task if these were to be administered and marked in the traditional fashion, so a Moodle-based online environment was used to administer, write and mark the quizzes. Moodle also gives automatic scoring and reporting facilities that can be explored in order to evaluate learning and teaching performances.

Lessons learned in the implementation and use of WIRIS quizzes with second-year students at the School of Industrial and Aeronautic Engineering in Terrassa at the UPC are shown. General information and curriculum of the degree in Aerospace Technology is shown in [20].

In Section II, the calculator and the WIRIS quizzes are shown, while Section III describes the Electrical Circuits course and the online hosting of the software. Section IV shows the implementation of the work and Section $\mathrm{V}$ presents the results obtained and lessons learned. Finally, Section VI draws conclusions.

\section{WIRIS QUIZZES AND CALCULATOR}

Electrical Engineering students and instructors use a browser to reach the local web server on which the system is hosted; on access, a screen appears with a login prompt. The calculator's instructor interface is shown in Fig. 1. The data in the questions are randomly generated (within a specified range) whenever a student accesses the question. Fig. 1 shows that variables can be random, for example, the frequency " $\mathrm{f}$ ", the rms voltage of the voltage source "v1m", etc. WIRIS quizzes generates different questions for each question introduced by the instructor, so quizzes can be personalized for each student using random data and conditional instructions (similar to those shown in Fig. 3). This question can be an activity, or belong to the set of questions in a quiz. 
WIRIS Quizzes (3)

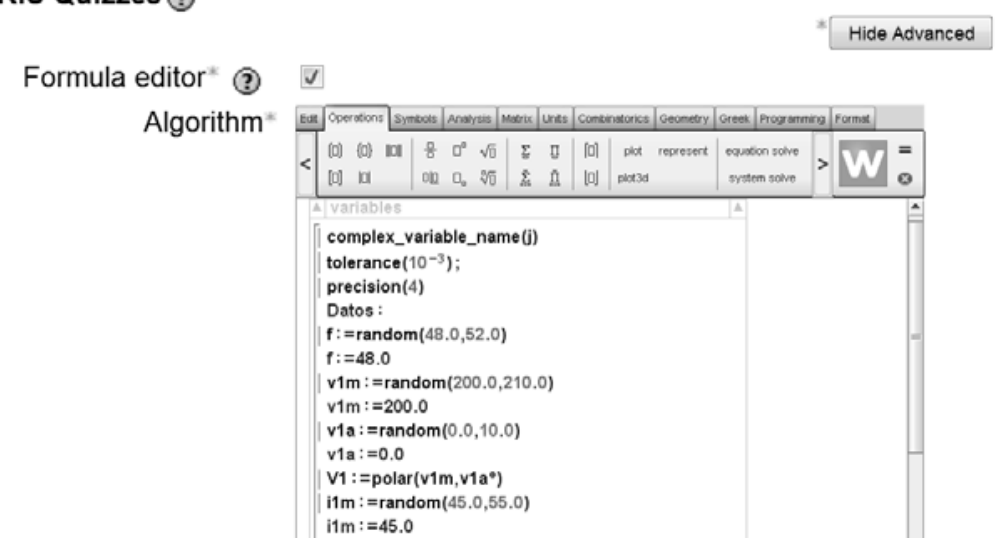

Fig. 1. WIRIS calculator instructor interface.

Assignments are not the traditional Moodle true / false or multiple choice exercises, but are generally designed to require one or more numeric responses. Also, more than one expression may be a valid answer to the quiz, for example the transient response of a circuit. WIRIS calculator is a powerful tool that offers many mathematical functions, e.g., the solution of differential equations [17], making it easier for students to solve practical problems despite the complexity of the mathematical solution.

When a student selects a quiz from the list, a screen appears showing the exercise, Fig. 2. First, the user is asked to find the Thevenin equivalent circuit at terminals A and B (question "a"). Second, the user is asked to give the value of a capacitor in parallel with the power source V1, which puts the voltage and current in phase (question "b").

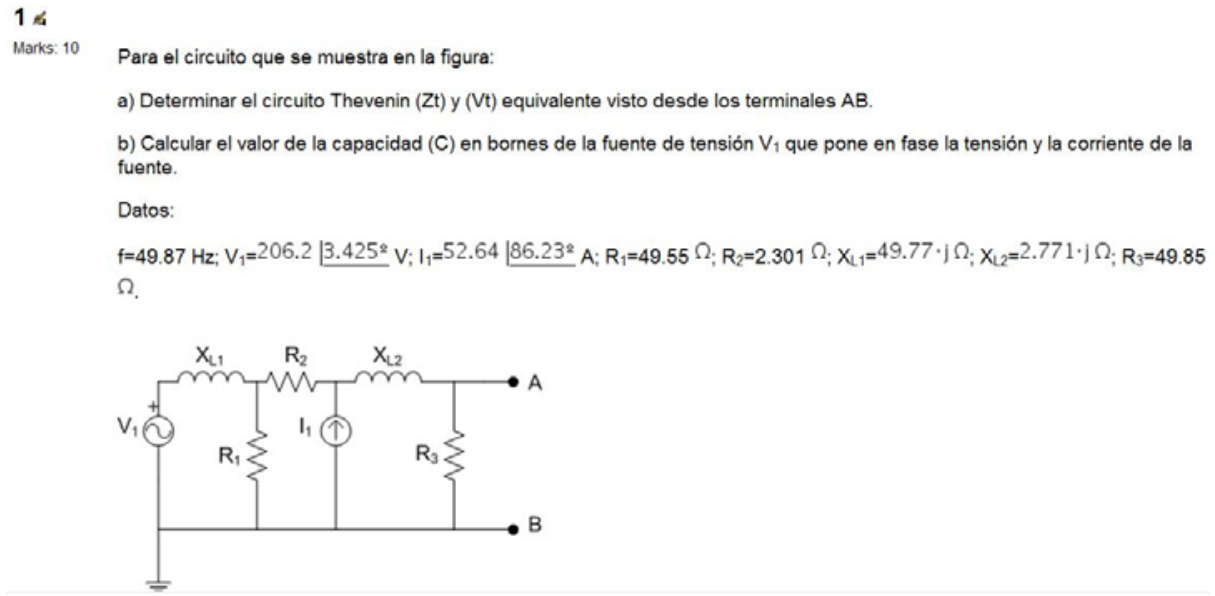

Fig. 2. Screenshot of the statement of an activity. 
The student does not need to do the exercise on paper to find the correct equations; s/he answers using the WIRIS calculator, and conditional instructions can even be used, as shown in Fig. 3. Students must learn a specific syntax to do the quizzes. Since the teacher has the same calculator as the student, the result obtained by the student of necessity matches the expected result.

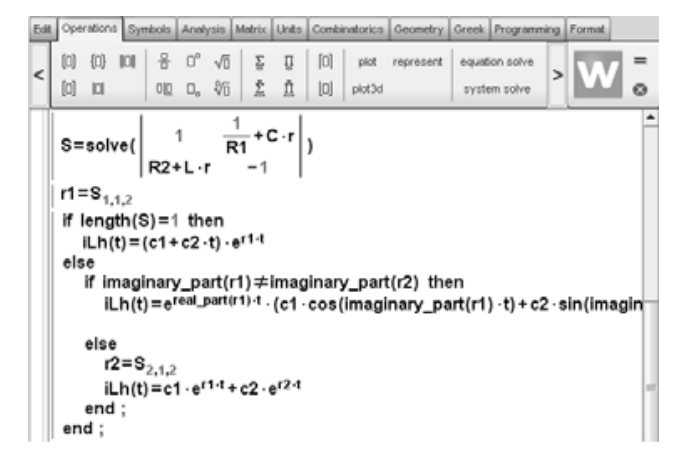

Fig. 3. WIRIS calculator.

The answer to the activity shown in Fig. 2 is copied into the answer area in Fig. 4. All the submitted answers are recorded, including equations for each attempt made, Fig. 5, providing very useful feedback for the teacher in making continuous improvements.

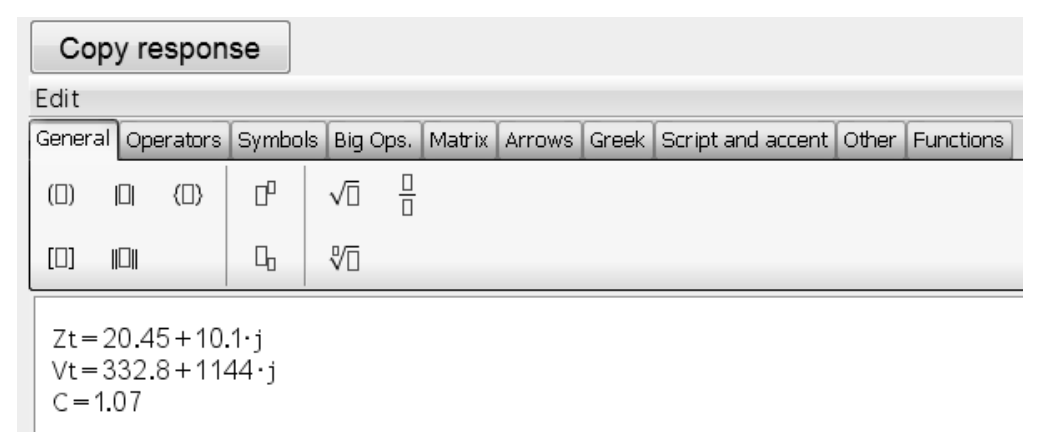

Fig. 4. Answer area for the activity. 


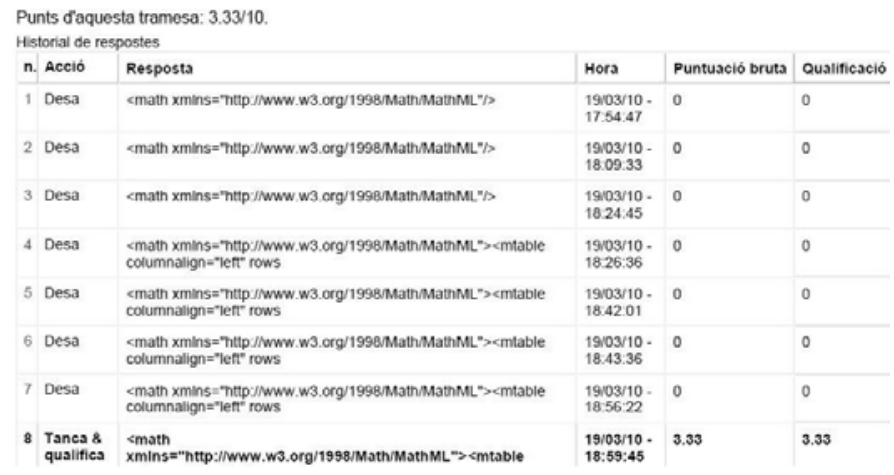

Fig. 5. Answer history of a WIRIS

Moreover, since the quizzes are automatically corrected and provide a grade, students know immediately whether they have achieved their objectives. Taras [21] commented that to achieve excellence it is always necessary to provide students with feedback on their performance. The system determines the amount of errors a student makes and generates messages for correct and incorrect answers. The system reports how many students correctly answered the exercises, and reports, for each student, when the quiz was submitted and how long the student took to complete it. In Fig. 5, the first column in the table shows the number of attempts, the second shows the action (saved or closed and submitted for grading), the third shows the link to the answer, which can be accessed by double clicking, the fourth shows the date and time of the attempt, the fifth shows the raw grade obtained and the sixth shows the final grade (raw grade with penalties if this option is adopted).

When the teacher accesses the student information s/he can view all the student attempts. In the example shown in Fig. 5 the student has made seven attempts and ends on the eighth (first column in the table in Fig. 5). The instructor can open all the attempts to view the complete mathematical progress towards the solution, and the numerical result. To do this, the teacher enters the student's attempt in a link that appears in the "resposta" (answer) column in this table. In the example shown in Fig. 2, the student had only solved the Thevenin impedance $(\mathrm{Zt})$ and had made mistakes with the Thevenin voltage $(\mathrm{Vt})$ and capacitance $(\mathrm{C})$. Therefore, the rating of this attempt was 3.33 out of 10 (ten points being the maximum mark). The student was not 
penalized with negative points for the mistakes made, so the values in the last two columns in the table in Fig. 5 are identical (3.33). Otherwise, the numbers in these columns would differ.

The teacher decided to give the student the correct answer after a set number of attempts. One very useful feature that was implemented was the ability to compile the results of multiple students. The instructor can see how many students did each exercise, what their answers were, how many completed the exercise and the nature of their errors. This information can be exported to Excel for statistical treatment by the instructor.

\section{ELECTRICAL CIRCUITS WEB}

The original problem statement begins with the concept of providing web-based quizzes for Electrical Engineering students. Electrical Engineering faculty members designed the quizzes and assignments while the WIRIS calculator and quizzes are produced by the company Maths for More [14]. UPC has a digital campus (ATENEA) dedicated to supporting academic requirements and enhancing active learning. This digital campus uses its own Moodle that also contains WIRIS quizzes and calculator. The Electrical Circuits course is offered during the second year of Aeronautical Engineering [20]. This course uses the textbook by Irwin and Nelms as a basic reference [22].

Electrical Engineering students can log in to web-based problem sets and select a quiz from a list of typical problem quizzes. Each quiz presents sufficient context for the student to solve the problem, guides the student through the solution, explains incorrect responses, and provides for instructor feedback and management.

Modules implemented include "single phase AC circuits", "three-phase systems" and "transient response of a circuit", along with a complex number annex, and assessment quizzes. Each topic consists of a single document with a theoretical summary, self-assessment quizzes, exercises and the forum theme. Seven quizzes have been realized in the current 2010-2011 academic 
year, each consisting of an exercise with several questions; the number of questions depends on the exercise to be analyzed. The quiz bank consists of fourteen AC single-phase circuit quizzes, eleven three-phase system quizzes and ten circuit transient response quizzes. Their aim is to introduce basic knowledge of the laws governing the behavior of electrical circuits. The exercises associate the application of electrical circuits to the industrial environment, with references to industrial websites containing technical and industrial information.

\section{IMPLEMENTATION}

In the 2009-2010 academic year, a pilot experiment was performed, with an experimental group of four student volunteers (out of a total of 46 students) who habitually did the quizzes, but did not contribute to the summative assessment.

In the current 2010-2011 academic year, to motivate the students to work on the quizzes, and to encourage them to use the WIRIS calculator, the decision was taken to grade the quizzes. Each quiz comprised $1 \%$ of the final course mark (thus a maximum of $7 \%$ of their final mark). In the current academic year (2010-2011) there were seventy-three students. Of the seven quizzes released progressively, sixty-six students tried at least one and fifty-three students attempted all of them, giving a larger experimental group than the previous year. Both courses have a different number of students, but their characteristics are similar. The teacher and the course syllabus are identical.

For students, the objective of the self-assessment quiz is to put into practice the knowledge acquired in practical sessions and to use the corresponding theoretical summaries. Active learning is enhanced by personalized quizzes, which can contain different data and response options for each student. There is no limit to the number of attempts allowed and each attempt builds on the last, so if the student is not satisfied with his/her grade or wants to learn to do the exercise perfectly, s/he may try again. The average time taken to perform a quiz is one hour, but 
since the quiz is enabled for a week the student can arrange his/her time to complete the quiz within that period.

Students must learn the WIRIS calculator syntax, especially the functions involved in solving electrical circuit exercises. After a twenty-minute classroom presentation, the students have a tutorial and are given the first quiz, which is pre-solved so they can use it as an example. The rest of the quizzes must be answered by students themselves (see Section II). Students can use their notes and books to answer the quizzes and can make queries while solving questions. Quiz answers are discussed in class, and key mistakes are especially highlighted.

In the teachers' opinion, the first quiz raised students' awareness of the difficulty involved, but they were not discouraged - as demonstrated by their ongoing participation in the remaining quizzes, and the number of attempts (an average of six) made until the exercise was solved successfully, Fig. 6. From Fig. 6, it can be concluded that the fifth quiz is the most difficult because it required more attempts to be solved correctly. This represents valuable feedback for the teacher.

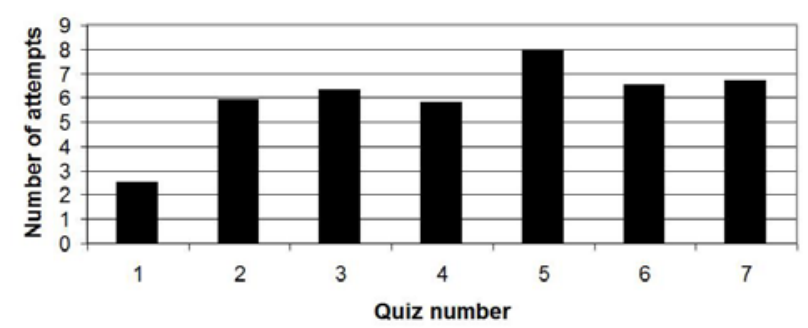

Fig. 6. Average number of attempts by students for each of the seven quizzes.

The assessment by students who performed the test was that it was positive for their learning. They commented on the difficulty of adapting to the WIRIS syntax, having no knowledge of computational tools such as Matlab [23] or Maple [24]. Previous knowledge of Maple would have made it easier to use WIRIS, as it uses a very similar syntax. This was the main reason why only 11 students completed the first activity in the pilot experiment (2009-2010 academic year) and 
only four persevered to form the experimental group.

\section{LEARNING AND FEEDBACK}

To assess whether the quizzes enhance learning, student grades for the quizzes were considered. Awarding marks from zero to ten, the grade range was established as follows: A: mark $\geq 9$; B: $7 \leq$ mark $>9$; C: $5 \leq$ mark $>7$; D: $3 \leq$ mark $>5$; and E: mark $<3$. Students failed with grades of $D$ and E. Fig. 7 shows the percentage of students achieving each range of marks for both quizzes and final grade (final result of the academic year). While for the quizzes the majority of students $(58 \%)$ are in range $A$, for the final grades the majority gain a grade $C(54 \%)$. The average grades for the quizzes are higher than for the final grade. It should be noted, though, that students are allowed to make as many attempts as they want to solve the quizzes correctly. Of the total number of attempts, regardless of the range of marks, $58 \%$ are in grade $\mathrm{A}$, compared to $22 \%(B), 11 \%(C), 0 \%(D)$ and $9 \%(E)$, so only $9 \%$ of attempts failed the quizzes (range $E$ ). Only $23 \%$ of the students had grades $\mathrm{D}$ and $\mathrm{E}$.

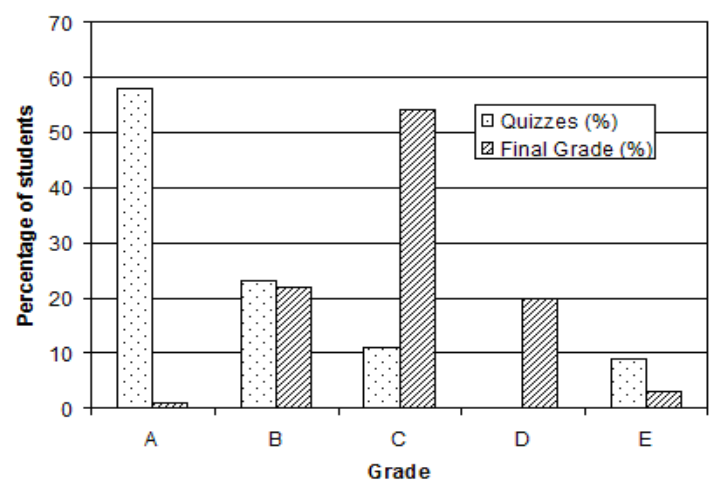

Fig. 7. Quiz and final course grades; percentage of students in each grade for both quizzes and final grade.

Fig. 8 is normalized independently for each grade to show the variation by grade in the numbers of attempts necessary for success. It shows the students' persistence in trying to perform well on the quizzes, making multiple attempts in order to get good grades. Over $45 \%$ of students who got an A grade for a quiz made from one to three attempts, 164 attempts out of 
368, Fig. 8. Over $25 \%$ of students who got an A grade for a quiz made from four to seven attempts. This means that $70 \%$ of students in the A grade made from one to seven attempts. Students obtaining a B grade needed to make more attempts that did those earning an A grade, Fig. 8 , since $33 \%$ made from 8 to 11 attempts and $47 \%$ made more than 12 attempts. These students needed a large number of attempts to achieve marks in the range of $\mathrm{B}$ and $\mathrm{C}$. Therefore, judging from the correlation between these data and correspondence with the final grade, it might be worth considering limiting the number of attempts in future courses.

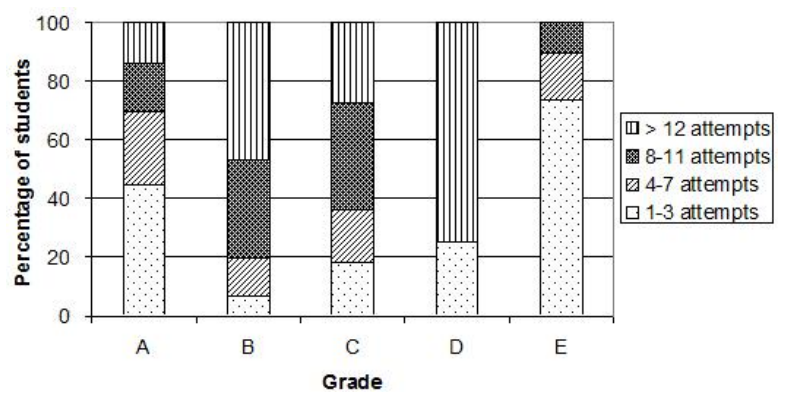

Fig. 8. Percentage of students in range of marks and number of attempts, Grade in quiz with quiz attempts normalized by range of marks.

It is important to know whether the effort made by students in the experimental group has an impact on the final grade for this course (2010-2011) compared to the previous year (2009-2010). In Section IV it was already explained that the characteristics of the students were similar, although the two courses did not have the same number of students. In Fig. 9, current students' final grades are compared with the previous academic year. On the current course, there are students who managed to obtain a mark in the A range. The number of students who obtained a mark in the $B$ range is higher: $11 \%$. If quizzes are marked, students tend to get higher grades overall. Therefore, a few more students moved into the $A$ and $B$ grade range, although the current course has 73 students as opposed to the 46 on the previous one. The failure rate decreased from $34 \%$ to $23 \%$. Therefore, it seems that online quizzes tend to enhance student learning. 


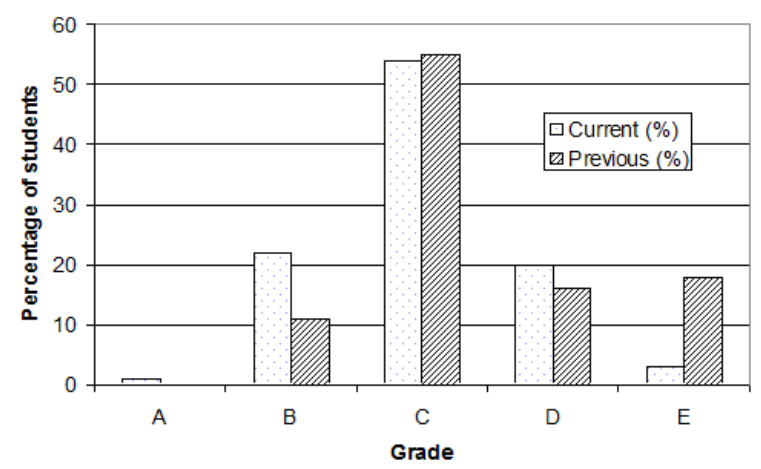

Fig. 9. Final subject marks in current (dots) and previous (lines) academic year

At the end of the semester, a survey was conducted to obtain feedback from the students. 61 students answered the survey, thus $83 \%$ of all students on the course (sixty-six students formed the experimental group). The survey consisted of statements that were scored from 1 to 6 , with 1 corresponding to strongly agree, 2 agree, 3 neutral, 4 disagree, 5 strongly disagree, and 6 corresponding to not knowing or not answering. The statements were:

1. Complementing the lectures with self-assessment quizzes is important to the student.

2. Self-assessment quizzes are useful to the student.

3. After doing the self-assessment quizzes the student feels surer of being able to pass the course.

4. Doing the self-assessment quizzes gave the student a sense of satisfaction because s/he feels more prepared for exams.

Table I shows the results discussed here, with S1 referring to statement number 1 in the survey and so on. For S1 more than $74 \%$ of students who answered the survey agreed or strongly agreed that self-assessment quizzes complement their training (1 and 2), 25\% were neutral or disagreed (3 and 4 ) somewhat and less than 1\% did not know or did not answer (6). More than $86 \%$ of students agreed or strongly agreed (1 and 2) that self-assessment quizzes were useful to them, $10 \%$ were neutral. These results show that students considered the self-assessment quizzes to be an important and useful complement to their training. More than $57 \%$ of students 
that responded to the statements strongly agreed or agreed that self-assessment quizzes made them feel sure that they were able to pass the course and $33 \%$ were neutral. More than $61 \%$ of students agreed or strongly agreed that self-assessment quizzes made them feel satisfied because they were more prepared for exams and $29 \%$ were neutral. These results indicate that students feel more prepared for and confident about the exam. Both are important. In fact, this has been another factor favorable to the rise in student grades compared with the previous year (2009-2010 academic course).

TABLE I

STUDENT FEEDBACK 2010-2011 ACADEMIC COURSE

\begin{tabular}{lcccc}
\hline \hline \multicolumn{1}{c}{ Degree of agreement } & $\begin{array}{c}\text { S1 } \\
(\%)\end{array}$ & $\begin{array}{c}\text { S2 } \\
(\%)\end{array}$ & $\begin{array}{c}\text { S3 } \\
(\%)\end{array}$ & $\begin{array}{c}\text { S4 } \\
(\%)\end{array}$ \\
\hline 1. Strongly agree & 28 & 43 & 10 & 23 \\
2. Agree & 46 & 43 & 47 & 38 \\
3. Neutral & 20 & 10 & 33 & 29 \\
4. Disagree & 5 & 0 & 3 & 5 \\
5. Strongly disagree & 0 & 2 & 2 & 0 \\
6. Don't know or no answer & 1 & 2 & 5 & 5
\end{tabular}

\section{CONCLUSIONS}

Teaching experience shows that students need a lot of time to calculate equations to solve problems, which delays their assimilation of subject-matter content. The quiz calculator has proven highly useful for solving this drawback. WIRIS quizzes have great potential for any technical degree since it offers suitable mathematical capabilities for university-level use. WIRIS quizzes develops personalized quizzes whose complex arithmetic operators, random data and conditional instructions constitute an improvement on Moodle. Seven WIRIS quizzes on electrical circuits that deal with the more complex topics on the course were integrated into the Atenea virtual campus at the UPC. WIRIS quizzes improves the way students self-assess and promotes the acquisition of knowledge through self-learning. This paper shows the development of these quizzes, the results of their use and their influence on the improvement of continuous 
assessment. Through the use of online quizzes a higher overall grade can be obtained than if the subject was addressed more traditionally.

WIRIS quizzes is a tool that provides students and instructors with feedback, so the quality of teaching is improved, both, at the lectures and in theoretical summaries. Overall, WIRIS quizzes is a valuable approach to learning and evaluation on such a skills-based course. This was reinforced by the student survey, which reflects an overall perception of enhanced learning, greater assurance and being prepared for exams through online quizzes.

Future improvements will consist of limiting the number of attempts and the time allowed, to make learning more efficient. Also, to make it easier to learn to use the WIRIS calculator, the authors will participate in an educational project for the generation of audiovisual material to help students learn how to use the tool.

\section{REFERENCES}

[1] J.J. Rodríguez, L. Gomes and S. Bogosyan, “Current trends in industrial electronics education,” IEEE Trans. Ind. Electron., vol. 57, pp. 3245-3252, Oct., 2010.

[2] Community site where Moodle is made and discussed. (2011, Dec. 7). [Online]. Available: http://moodle.org/?lang=en_us

[3] M. Blanco, M.R. Estela, M. Ginovart and J. Saà, "Computer assisted assessment through Moodle quizzes for calculus in an Engineering Undergraduate Course,” in Int. Commission for the Study of Improvement of Math. Educ., Montreal (Canada), 2009, pp. 78-83.

[4] R. Sharma. Impact of using Moodle as an educational management tool to enhance learning for on campus and external mode electrical students at USQ. presented at the Engineering Education 2010. [Online]. Available: http://www.engsc.ac.uk/downloads/scholarart/ee2010/28_GP_Sharma.pdf

[5] M. Llamas et al., "Use of LMS Functionalities in Engineering Education,” in 41st ASEE/IEEE Frontiers in Educ. Conf., 2011, pp. 1-6.

[6] V. Aravinthan and T. Aravinthan. Effectiveness of self- assessment quizzes as a learning tool. presented at the Engineering Education 2010. [Online]. Available: http://www.engsc.ac.uk/downloads/scholarart/ee2010/31_GP_Aravinthan.pdf

[7] M. Peat et al., "Revisiting the impact of formative assessment opportunities on student learning," Australasian Journal of Educational Technology, vol. 21, no.1, pp. 102-117, March 2005.

[8] D. Woit and D. Manson, "Enhancing student learning through on-line quizzes," in Proc. 31st SIGCSE Technical Symposium on Computer Science Education, vol. 32, no.1, 2000, pp. 367-371.

[9] Q. Xu, L.L. Lai, N.C.F. Tse and K. Ichiyanagi, "A Multiple-Sessions Interactive Computer-Based Learning Tool for Ability Cultivation in Circuit Simulation,” IEEE Trans. Educ., vol. 54, no.1, pp. 56-62, Feb. 2011.

[10] A. Bentounsi et al., "Computer-Aided Teaching Using MATLAB/Simulink for Enhancing an IM Course With Laboratory Tests,” IEEE Trans. Educ., unpublished.

[11] E. C. Shaffer and F. J. Mabry, “A student designed, Web-based learning program for circuit analysis,” in 30th Annual Frontiers in Education Conf., vol. 1, 2000, pp. 17-22.

[12] L. Weyten, P. Rombouts and J. De Maeyer, "Web-based trainer for electrical circuit analysis,” IEEE Trans. Educ., vol. 52, no.1, pp. 185-189, Feb. 2009.

[13] L. Weyten et al., "Validation of Symbolic Expressions in Circuit Analysis E-Learning," IEEE Trans. Educ., unpublished.

[14] WIRIS Quizzes home. (2011, Dec. 7). [Online]. Available: http://www.wiris.com/es/quizzes

[15] WIRIS in UPC. (2011, Dec. 7). [Online]. Available: http://wiris.upc.es/

[16] M. R. Estela, J. Saà and J. Villalonga. (2009, Oct.). Wiris Quizzes. Assessing mathematics through Moodle quizzes. [Online]. Available: www.mit.edu/ jsaa/papers/WQ.pdf

[17] M. R. Estela, Fonaments de càlcul (2nd ed.), Barcelona: Aula Politècnica, 80, 2005.

[18] Mathematical objects of wiris. [Online]. Available: http://www.wiris.net/wiris/manual/en/html/tour/objectesmatematics.html\#polinomis. Last visit: October 2011.

[19] Programming with Wiris. (2011, Dec. 6). [Online]. Available: http://www.wiris.net/wiris/manual/en/html/tour/wirisplus.html

[20] General information and curriculum of the degree in Aerospace Technology. [Online]. Available: http://www.etseiat.upc.edu/futurs estudiants/degree-in-aerospace-technology-masters-degree-in-aeronautical-engineering.pdf. Last visit: October 2011.

[21] M.Taras, "Using Assessment for Learning and Learning from Assessment," Assessment \& Evaluation in Higher Education, vol. 27, no.6, pp. 501-510, 2002.

[22] J.D. Irwin and R.M. Nelms, Basic Engineering Circuit Analysis (9th ed.). John Wiley \& Sons, 2011.

[23] Website of MathWorks, the developer of Matlab. (2011, Dec. 7). [Online]. Available: http://www.mathworks.com/

[24] Website of Maplesoft. The Maplesoft product suite includes Maple. (2011, Dec. 7). [Online]. Available: http://www.maplesoft.com/ 
Santiago Bogarra Rodríguez received the Ph.D. degree from the Polytechnic University of Catalonia, Barcelona, Spain, in 2002. Currently, he is an Associate Professor of Electrical Engineering with the Polytechnical University of Catalonia. His research interests include renewable energy, power quality and power system operation and control.

Montserrat Corbalán Fuertes (M’10) was born in Teruel, Spain. She received the M.S. degree in Physics in 1990 and the Ph.D. degree in Physics from the Polytechnic University of Catalonia (UPC) in 1997. She is currently a Senior Lecturer (TU) in the Electronics Department at the UPC. Her work has been in the areas of image processing, characterization of image capture systems, and color image recognition by optical correlation. Currently, her research interests also include quality in education. She belongs to the research group EduQTech devoted to research in and the application of quality in education and in technology. She is a member of the IEEE Education Society.

Antoni Font Piera received the B.S. degree in Industrial Engineering from the Polytechnic University of Catalonia (UPC) in 1982. Currently, he is an Associate Professor of Electrical Engineering with the Polytechnical University of Catalonia. His research interests include transformer saturation.

Inmaculada Plaza (M’02-SM'06) received the M.S. degree in Physics, the Advanced Studies Diploma (DEA) in Design and Manufacturing Engineering, and the Ph.D. degree in Electronic Engineering from the University of Zaragoza. She was a quality consultant and leader in a security firm. She is currently a Senior Lecturer (TU) in the Electronics Department at the Polytechnic University School of Teruel, University of Zaragoza. Her research interests include quality in R\&D\&I activities, quality of life and quality in education. Along with Dr. Francisco Arcega, she is the Coordinator of the research group EduQTech. Currently Inmaculada Plaza is Chairwoman of the Spanish Chapter of the IEEE Education Society.

Francisco J. Arcega (M’76-SM’05) was born in Caspe (Zaragoza), Spain. He received the M.Sc. in Physics in 1976 and his Doctorate in 1981 in University of Zaragoza, Spain. In 1976 he joined the Electronics Department of the University of Zaragoza and since 1982 he has been in the Electrical Engineering Department where he is currently a Professor (CEU). His main research interests are in the field of electrical measurements and their applications in industry. He is also involved with quality in education and in laboratory activities. He is co-director of the research group EduQTech. Dr. Arcega was Director of the Department of Electrical Engineering and later Dean of the Faculty of Engineering (EUITIZ) in the University of Zaragoza (2004-2009) and is a member of the Directive of the Spanish Chapter of the Education Society of the IEEE. He has published many papers in education and in electrical engineering, mainly in with the areas of quality and measurements. He has published a book on sensors and another on metrology. 